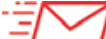

\section{Truffles and climate change}

The Burgundy truffle (Tuber aestivum syn T uncinatum; Wedén et al. 2005) rates highly amongst the world's most precious culinary delicacies. Currently, specimens are valued around $€ 600$ ( US\$820) per kilogram, depending on production rate, culinary quality, and consumer demand. In contrast with that of the Périgord black truffle ( $T$ melanosporum) and the Piedmont white truffle (T magnatum), the natural habitat of the Burgundy truffle is less well recognized (Figure 1a). Indeed, surprisingly little is known about the physiology and ecology of many Tuber spp (Phylum Ascomycota; Bertault et al. 1998; Martin et al. 2010), in part because of their hypogeous (belowground) life cycle (Trappe and Claridge 2010) and the general lack of knowledge regarding the drivers of fruiting-body growth in ectomycorrhizal fungi (Gange et al. 2007).

A trained truffle dog (breed: Lagotto Romagnolo), attracted by the intense smell of numerous volatile compounds emitted by the hypogeous fruiting body, detected a mature $T$ aestivum specimen (weight: $414 \mathrm{~g}$; volume: $407 \mathrm{~cm}^{3}$; diameter: $\sim 10 \mathrm{~cm}$; value: €200 [ US\$274]; Figure 1, b-d) within a mixed oak/beech forest in southwest Germany, near Lake Constance $\left(47.72^{\circ} \mathrm{N}, 8.88^{\circ} \mathrm{E}\right)$. The testaceous gleba (or spore-bearing tissue) with light venation was perfectly developed, and the distinctive ring structures visible on the surface (Figure 1e) may possibly indicate growth increments. An additional 2 $\mathrm{kg}$ of Burgundy truffle was collected in the surrounding area, with individual weights between $5 \mathrm{~g}$ and $80 \mathrm{~g}$. Existence of Burgundy truffle north of the arc of the European Alps and west of Lake Constance has hitherto rarely been reported. Between August and December 2010, we conducted sporadic dog-based surveys for truffles, which revealed $>70$ sites of seven Tuber spp including $T$ aestivum, $T$ brumale, $T$ excavatum, $T$ fulgens, $T$ macrosporum, $T$ mesentericum, and $T$ rufum. The discovery of mature $T$ brumale specimens in early November was a particular surprise, given that this species usually fruits from January-March.

Whether an anomalously warm summer and cold autumn (Figure 1f), in conjunction with a precipitation surplus, proved conducive to producing such an unusually large truffle specimen remains speculative. However, the discovery of numerous smaller fruiting bodies in the same area may be indicative of a climateinduced species' range expansion. We hypothesize that plentiful truffle harvest - now for the first time documented in southwest Germany, far outside the traditional cultivation region - may not simply be related to short-term weather variations but rather could be a result of longer-term climate change, given that belowground truffle fruiting under favorable soil conditions appears to be generally insulated from weather fluctuations. The truffle-host symbiosis and associated carbohydrate metabolism, however, complicate tracking climate responses due to lag effects, since the fungi must compete with the host plant's water and carbon demands. Soil characteristics (eg temperature, moisture) and microorganism activities may also enhance or inhibit subterranean mycelial growth and fungal fruiting (see Figure 2 for a schematic overview of truffle ecology).

Evidence of Burgundy truffle presence in southwest Germany - a region where Tuber spp are classified as Very Rare or even Extinct on the IUCN Red List - may suggest a climateinduced biome shift, in line with extended growing-season length (Peñuelas et al. 2009), likely triggered by increasing average temperatures (Fischer and Schär 2009). Recent truf-

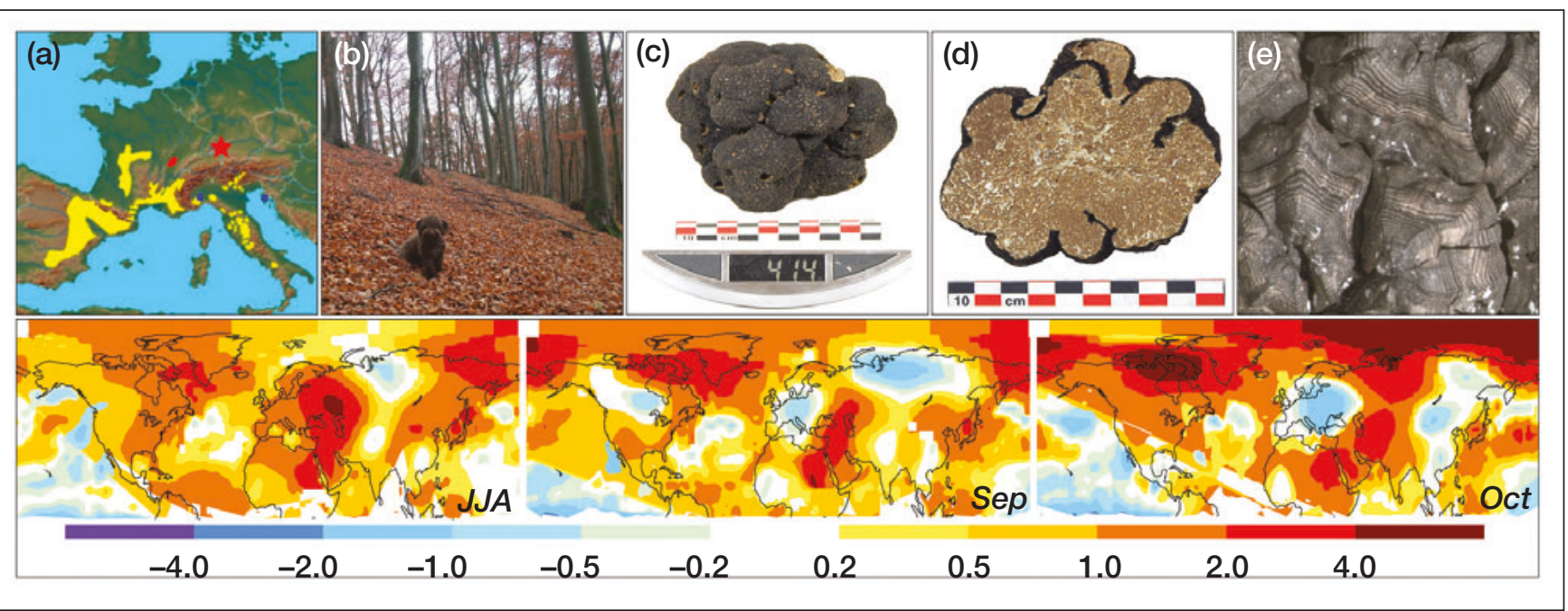

Figure 1. (a) Distribution of Périgord black truffle (yellow) and Piedmont white truffle (blue), and the traditional range of Burgundy summer truffle (red). The star indicates the find location in Germany, with a trained truffle dog $(b)$. Full (c) and cross-section (d) images of the specimen, showing the gleba (spore-bearing tissue). (e) Microscopic amplification of truffle peridium (surface) reveals horizontal black/gray layers that, to our knowledge, have never been reported before, and may represent growth increments. (f) Temperature anomalies of 2010 with respect to 1901-2000, as obtained from the Goddard Institute for Space Studies (www.giss.nasa.gov/). JJA = June-August. 


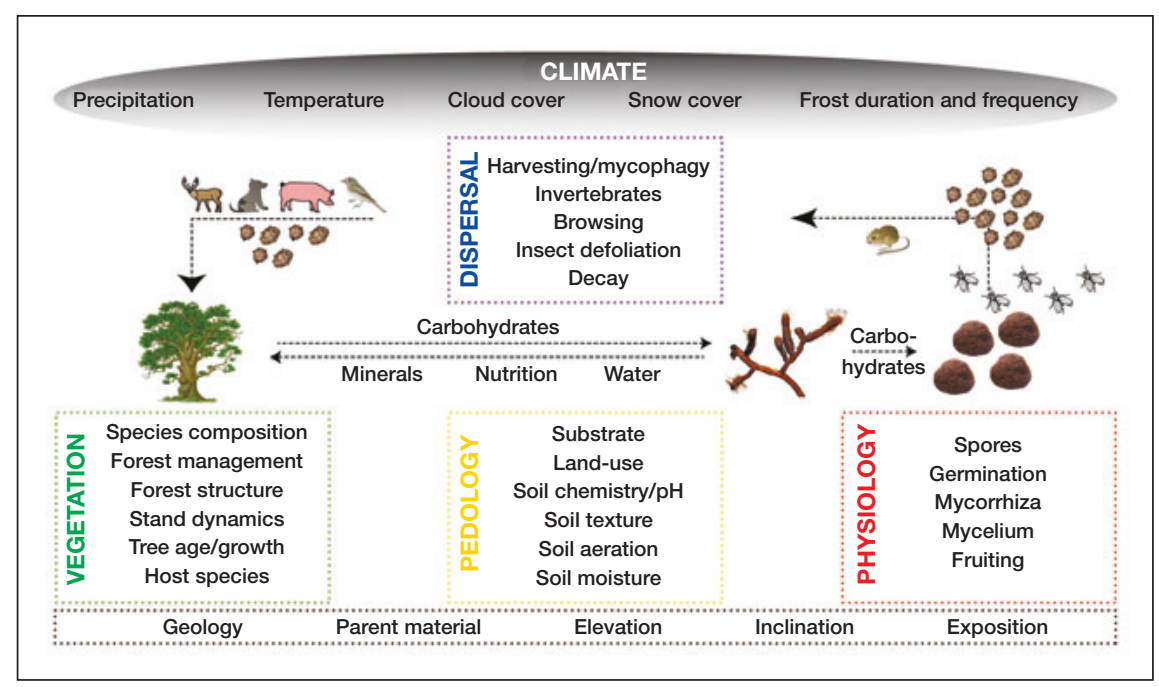

Figure 2. Holistic perspective of the numerous, interrelated biotic and abiotic factors that drive truffle productivity and phenology.

fle findings as far north as Gotland (a Baltic island off the southeast Swedish coast) further suggest a close link to environmental change (Wedén et al. 2005). Assessment of high-resolution climatic data (Mitchell and Jones 2005) revealed spatial differences of $\sim 0.5^{\circ} \mathrm{C}$ between mean temperatures in Burgundy and our study site, which corresponded with temporal changes in mean temperatures observed in Europe between the early and late 20th century. An average warming trend of $0.5^{\circ} \mathrm{C}$ per century, depending on seasonal, regional, and methodological constraints, would translate in an isothermal upward (northward) shift of $\sim 100$ miles $(\sim 110 \mathrm{~km})$. Various model simulations forecast a substantially warmer 21st century (Fischer and Schär 2009), which would likely continue to alter the geographical, ecological, and physiological range of mycorrhizal fungi and their host plants.

Projected environmental changes across the Mediterranean truffle fociwhere future temperature and precipitation rates are expected to rapidly increase and decrease, respectively (Giorgi 2006) - will be critical for truffle species with limited dispersal capabilities, such as $T$ melanosporum or $T$ magnatum. Likewise, declining harvests will boost the economic value of truffles. Understanding different ecosystem responses to projected climate change (ie with opposing sig- nals south and north of the Alps), as well as the complex interplay of biotic and abiotic factors (Figure 2), is thus of enormous scientific, economic, and gastronomic importance (Hall et al. 2003; Trappe and Claridge 2010).

Our findings encourage rethinking the distribution and dynamics of European truffle populations, provide insight into the dark world of hypogeous fungi, and appear relevant to truffle cultivation efforts. Formerly time-consuming, expensive, and with little guarantee of success, truffle plantations may become more promising for $T$ aestivum and even feasible for $T$ melanosporum in a warmer climate north of the Alps.

Ulf Büntgen ${ }^{1,2^{*}}$, Willy Tegel ${ }^{3}$,

Simon Egli ${ }^{1}$, Ulrich Stobbe ${ }^{4}$,

Ludger Sproll ${ }^{4}$, and

Nils C Stenseth ${ }^{5}$

${ }^{1}$ Swiss Federal Research Institute for

Forest, Snow and Landscape,

Birmensdorf, Switzerland

*(buentgen@wsl.ch); ${ }^{2}$ Oeschger

Centre for Climate Change Research,

Bern, Switzerland; Institute for Forest

Growth, University of Freiburg,

Freiburg, Germany; ${ }^{4}$ Chair of Forest

Botany, University of Freiburg,

Freiburg, Germany; ${ }^{5}$ Centre for

Ecological and Evolutionary Synthesis,

University of Oslo, Oslo, Norway

Bertault G, Raymond M, Berthomieu A, et al. 1998. Trifling variation in truffles. Nature 394: 734.

Fischer EM and Schär C. 2009. Future changes in daily summer temperature variability: driving processes and role for temperature extremes. Clim Dynam 33: 917-35.

Gange AC, Gange EG, Sparks TH, and Boddy L. 2007. Rapid and recent changes in fungal fruiting patterns. Science 316: 71.

Giorgi F. 2006. Climate change hot-spots. Geophys Res Lett 33: L08707.

Hall IR, Yun W, and Amicucci A. 2003. Cultivation of edible ectomycorrhizal mushrooms. Trends Biotechnol 21: 433-38.

Martin F, Kohler A, Murat C, et al. 2010. Périgord black truffle genome uncovers evolutionary origins and mechanisms of symbiosis. Nature 464: 1033-38.

Mitchell TD and Jones PD. 2005. An improved method of constructing a database of monthly climate observations and associated high-resolution grids. Int J Climatol 25: 693-712.

Peñuelas J, Rutishauser T, and Filella I. 2009. Phenology feedbacks on climate change. Science 324: 887-88.

Trappe J and Claridge AW. 2010. The hidden life of truffles. Sci Am 302: 78-84.

Wedén C, Danell E, and Tibell L. 2005. Species recognition in the truffle genus Tuber - the synonyms Tuber aestivum and Tuber uncinatum. Environ Microbiol 7: 1535-46.

doi:10.1890/11.WB.004

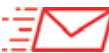

\section{Plastic: matching material with usage}

We are in the midst of a global plastic pollution crisis. Plastic consumption has doubled over the past three decades (Thompson et al. 2009) and, as a result, large areas of our terrestrial and aquatic environments are now overrun with discarded plastic. Although plastic pollution in the environment is an issue that must be addressed, the substance plays an integral role in human lives and technology. For example, in automobiles, plastic replaces metal parts to increase fuel efficiency by decreasing weight (see www.bpf.co.uk). Thus, a total ban on plastic would be impractical. How, then, should we try to curb global plastic consumption? A sensible way to alleviate consumption would be to identify those products for which its usage is unnecessary.

It is now a common practice to use millennia-lasting plastics for everyday items, such as bags or disposable 